\title{
Alexandra Colony: Resiliencia en el norte de la Provincia de Santa Fe (1866-1904), Argentina
}

\section{Alexandra Colony: Resilience in the North of the province of Santa Fe (1866-1904), Argentina}

Irene Dosztal|* (http://orcid.org/0000-0002-9086-259X)
Recibido el 13 de octubre de 2015. Aceptado el 18 de mayo de 2016.

"Autor para correspondencia: Irene Dosztal, correo electrónico: dosztal@ishir-conicet.gov.ar

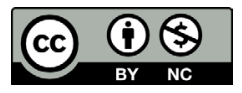

Todos los contenidos de Estudios Fronterizos se publican bajo la licencia Creative Commons Atribución no comercial 2.5 México, y pueden ser usados gratuitamente para fines no comerciales, dando el crédito a los autores y a la revista Estudios Fronterizos.
${ }^{1}$ Unidad de Investigación en Historia Regional (Ishir) y Consejo Nacional de Investigaciones Científicas y Técnicas (Conicet), Buenos Aires, Argentina, correo electrónico: dosztal@ishir-conicet.gov.ar

\section{Resumen}

En este artículo se desarrollan los aspectos teóricos desde una perspectiva histórico-antropológica, que anticipa un espacio fronterizo con una diferenciada estructura económica, social y cultural, donde se desenvuelven la vida y experiencias de familias de colonos que se instalan a $90 \mathrm{~km}$ del límite territorial septentrional controlado por el gobierno de la Provincia de Santa Fe. En la frontera norte de Santa Fe se combate el "desierto", en primer lugar, con la fundación de colonias agrícolas por contrato y, luego, con el avance militar. Por lo que se elige el concepto de frontera de colonización para analizar el rol de las colonias que junto a Alexandra Colony la conforman. Partiendo de la revisión de los estudios de frontera, se focaliza en el carácter resiliente de los grupos sociales enfrentados por fuera de la última línea de fortines al norte de la Provincia de Santa Fe donde se fundan colonias agrícolas.

Palabras clave: frontera de colonización, resiliencia, colonización oficial, Provincia de Santa Fe.

\section{Abstract}

In this article the theoretical aspects are developed from a historic-anthropological perspective, which anticipates a frontier space with a differentiated economic, social and cultural structure, where they operate the life and experiences of families of settlers who are $90 \mathrm{~km}$ of the Northern territorial limit controlled by the Government of the province of Santa Fe. In the north border of Santa Fe the "desert" fights, first, with the foundation of agricultural colonies for contract and, then, with the military advance. Therefore, the concept of border of colonization is chosen to analyze the role of the colonies that

CÓMO CITAR: Dosztal, I. (2016). Alexandra Colony: Resiliencia en el norte de la Provincia de Santa Fe (1866-1904), Argentina [Alexandra Colony: Resilience in the North of the province of Santa Fe (1866-1904), Argentina]. Estudios Fronterizos, 17(34), 117136, https://doi.org/10.21670/ref.2016.34.a07 
make it up next to Alexandra Colony. Based on the review of the studies of border, focuses on the character resilient of social groups facing out of the last line of forts to the North of the province of Santa Fe, where the agricultural colonies were founded.

Keywords: border of colonization, resilience, official colonization, province of Santa Fe.

\section{Introducción}

El Estado argentino de la segunda mitad de siglo XIX establece un plan político, económico y social que le permitiese ingresar al mercado mundial. Esto implica ingresar a la era del capital, es decir, entrar a una era alienadora en lo económico y en lo cultural que, por un lado, posibilitó la expropiación de tierras y la transculturalización ${ }^{2}$ de una comunidad indígena desposeída y no reducida ${ }^{3}$ que transitaba y vivía en el "desierto" y, por el otro, instaló los dispositivos de una sociedad agro-exportadora capitalista moderna, que implantó el germen para la fundación de las instituciones que, hasta la actualidad, rigen en la sociedad argentina.

La frontera entre blancos e indios — que, en ese marco, ya no tenía por qué existirfuncionó, simultáneamente, como límite geográfico y social, pero se mantuvo como una barrera permeable. Si bien su objetivo fue mantener diferenciada la "civilización" de la "barbarie", no pudo impedir que los distintos grupos sociales interactuaran, por lo que se produjo una organización muy compleja de relaciones sociales y de conducta.

La dicotomía que convierte a un grupo con una identidad diferente de quien enuncia en un otro, supone el reconocimiento de ciertas limitaciones y acuerdos necesarios para llegar a un entendimiento recíproco (político, económico o socio-cultural). Sin embargo, en este caso, los juicios de valor emitidos por el grupo dominante llevaron al exterminio de ese otro compuesto por diferentes grupos étnicos. Esto convirtió a la problemática de la dilución de la frontera en una cuestión de Estado.

Dado que esta frontera no solo fue parte del discurso político, sino que también se materializó entre los siglos XVIII y XIX y dejó huellas en el terreno que ocupaba y en sus pobladores, este trabajo da cuenta de las particularidades de una frontera de colonización tanto desde una perspectiva teórica-práctica y de las consecuencias en el devenir de las colonias que junto a Alexandra Colony formaron parte de ella.

Se parte de un análisis de propuestas teóricas que nos permitieron comprender la complejidad del poblamiento con extranjeros de un territorio que estaba habitado por parcialidades indígenas que resistieron su ocupación. Para delinear, luego, las particularidades del caso estudiado.

Previo a este desarrollo teórico, se presentan las condiciones de fundación de Alejandra Colony dentro del proyecto colonizador que llevan adelante los sucesivos gobiernos de la provincia de Santa Fe en el periodo estudiado.

\footnotetext{
${ }^{2}$ La transculturación es un fenómeno que sucede cuando un grupo social recibe y adopta por imposición las formas culturales que provienen de otro grupo. La comunidad, por lo tanto, termina sustituyendo en mayor o menor medida sus propias prácticas culturales.

${ }^{3}$ Grupos indígenas no dominados por la sociedad occidental hegemónica de siglo XIX.
} 


\section{Alexandra Colony, su contexto de fundación}

El banco londinense Thomson, Bonar \& Co., con sede en la ciudad de Buenos Aires, financia el proyecto colonizador Alexandra Colony. Con la designación de su nombre la empresa le rinde homenaje a la futura reina consorte, Alexandra de Dinamarca, esposa del rey-emperador Edward VII. Alexandra fue popular y querida entre los británicos. De carácter generoso y caritativo, llevó adelante su función pública en pro de clases desprotegidas (Hough, 1992). En otro orden, su belleza llamó la atención de todos desde su llegada (Madol, 1940), y su estilo en el vestir impuso una moda por más de 50 años; como lo fue el uso de gargantilla que cubría su cuello y escotes (Dosztal, 2015).

El contrato de colonización se aprueba por el gobernador Simón de Iriondo, en él se delimita la propiedad de 25 leguas cuadradas frente al río San Javier, y estableció el compromiso de los empresarios de asentar, en un lapso de cinco años, a 400 familias de inmigrantes europeos. El terreno linda, al sur, con la propiedad de Ovidio Warnes y Cía. y, al norte, con el arroyo de Malabrigo. En la delineación de la colonia, se le asigna a cada familia colona 25 cuadras cuadradas a pagar con financiamiento, una vez realizada la concesión (Wilcken, 1873).

En los años previos se fundan tres colonias - California, Galesa y Eloisa- en el territorio que se extendía desde la línea de fortines norte (a la altura del pueblo indígena de San Javier), hasta el límite sur de Alexandra Colony. En su conjunto formaron un círculo social, económico, étnico, identitario y político consecuente al perfil poblacional buscado por la clase dirigente (Dosztal, 2013). Estas colonias se crean en el marco en un programa fomentado por el gobierno provincial conocido como colonización oficial, donde el Estado cumple una función clave de regulación y control de los contratos en este periodo. $\mathrm{Al}$ respecto:

En la provincia de Santa Fe se practicaron principalmente dos tipos de colonización; una oficial y otra privada. Prevaleciendo la primera de ellas en nuestra zona de interés: el norte santafesino. En la colonización oficial el Estado actuaba como intermediario a través de las concesiones de tierras a empresario o compañías colonizadoras (Dosztal, 2010, p.1517).

Las tierras fiscales vendidas bajo este sistema colonizador se compraban a mínimo costo y los empresarios debían cumplir ciertas obligaciones respecto de la cantidad de pobladores a establecer, así como de las facilidades de vivienda, entrega de semillas y herramientas al colono y su familia (Ensinck, 1978; Zeballos, 1984). Para implementar estos requisitos y para comerciar los productos, el Estado crea las denominadas casas centrales de administración. Las mismas cumplen un papel significativo principalmente en esta primera etapa de colonización oficial (1850-1870), cuando unas pocas colonias estaban aisladas en la inmensidad del territorio (Gallo, 2004).

La mayor proporción de colonias se fundan entre 1870 y 1895 con el proceso denominado colonización privada, en el que el rol del Estado sufre un drástico desplazamiento limitándose a eximir al empresario del pago del impuesto de contribución directa si las tierras estaban por fuera de la línea de frontera y a quienes iniciaran actividades comerciales e industriales (Larguía, 1876). Este drástico cambio en el sistema puede ser asociado a que las colonias se fundaban con rapidez rompiendo el aislamiento y generando colonos experimentados que trasmitían sus conocimientos, por lo que la presencia de casas centrales de administración ya no era compatible con la ligereza vivida a partir de la década de 1880 (Gallo, 2004). 
Alexandra Colony sufre inconvenientes en 1871 en un enfrentamiento con indígenas locales y quince años después, la sociedad Thomson, Bonar \& Co. decide vender su propiedad en tierras santafesinas. Este contexto fundacional condiciona a administradores y colonos, debido a que se encuentran ante la necesidad de combinar sus ocupaciones diarias con la imposición de una función de defensa de carácter controversial, en un territorio que se les otorgó a través de la firma de contratos de colonización. Puede decirse, por consiguiente, que Alexandra Colony debe resistir las situaciones sociales, económicas, políticas y diplomáticas adversas. En este panorama, los colonos cumplen un rol central, ya que son los que trabajan para llevar adelante el proyecto. Son, por tanto, quienes elevan sus quejas a los Jueces de Paz sobre los abusos de los administradores (Tourn, 2001); quienes se organizan para combatir al enemigo común (los grupos indígenas sin hacer diferencia en su identificación étnica); quienes le permiten al Estado usufructuar tierras que, oficialmente, no controla y quienes le brindan el tiempo necesario para organizar la ocupación militar de la región chaqueña. Pese a que el gran proyecto de colonización agrícola fracasa, la combinación de una agricultura y ganadería intensivas con el colonialismo inglés permite que con la fundación de Alexandra Colony se controlara y explotara un territorio que hasta esos tiempos se encontraba en manos de los pueblos guaycurúes originarios de la región.

\section{Estudios sobre áreas fronterizas: Antecedentes}

Los abordajes que se llevaron a cabo de la década de los setenta hasta la actualidad plantearon a la frontera desde una problemática político-social, como un espacio en constante interacción con el medio geográfico, social y económico que lo rodea, y como un límite territorial (Alemán, 1970 y 1981; Benedetti, 2007; Mateo, 1997; Ratto, 1996 y 2003; Weber, 1986). ${ }^{4}$ Por tanto, se le otorga entidad materializada al espacio y al tiempo a partir de que los actores sociales (tenientes, comandantes, caciques, presidentes y gobernadores) que entablaron una relación de dominados y dominantes derivada de la incorporación al mercado mundial.

Esta necesidad de vinculación internacional lleva a concretar la conquista de territorios por parte de la burguesía local con el avance de la civilización entre el último tercio del siglo XIX y principios del XX, tanto al sur como al norte del país, con objetivos varios; uno de ellos, fue la expropiación de las condiciones materiales y culturales, ubicando a la población indígena en una formación de clase: la de los expropiados. Es decir, la burguesía local aliada al modo capitalista de producción, permite que este fuese sucesivamente subsumiendo procesos de trabajo y relaciones de intercambio preexistentes tratando de refuncionalizarlos hasta acabar con la frontera interior (Trinchero, 2007). "Históricamente ese proceso comienza con la división de la sociedad en estamentos y clases distintas cuando, como resultante del desarrollo de las fuerzas productivas, se produce la disolución y superación de la comunidad primitiva" (Iñigo, 1989, p. 2). Por lo que el estudio sobre la vida en la frontera posibilita un análisis de clases sociales y de sus vínculos con el Estado.

El examen del valor en sus tiempos y con sus protagonistas conlleva a considerar cómo jugaban tierra, ganado y trabajo en la campaña del sur y qué capacidad

\footnotetext{
${ }^{4}$ La bibliografía publicada en Argentina sobre estudios de frontera supera los objetivos del artículo, por lo que
} la selección citada responde a una relación contundente con la especificidad del caso bajo estudio. 
tenía el Estado para movilizarlo y capturarlo en dirección a una interés de clase (Rocchietti, 2008, p. 103).

Para que esto sea posible, se hace necesario superar la simpleza del mundo rural argentino, su atraso y su barbarie a través de su incorporación a un sistema de relaciones capitalistas, modificando por completo la propiedad de la tierra ya que oponía el derecho racional al de la tradición; y es justamente el Estado nación la entidad desde la que se debe emanar este derecho. Este proceso sólo puede construirse "si se vincula el proceso de conquista militar y sometimiento de la población indígena al momento por el que transita el desarrollo del capitalismo argentino" (Iñigo, 1989, p. 5); lo que va modificando la economía regional basada en la caza, la recolección, una incipiente agricultura y la guerra, "como actividad que permitía obtener y mantener su principal condición de producción (la tierra), y cuya forma de organización era la tribu [...]” (Iñigo, 1989, p. 1).

El espacio fronterizo que se entiende desde esta concepción convergente de múltiples aspectos supera el ámbito de lo ecológico y puede ser abarcado como una problemática social entre espacios caracterizados por dinámicas productivas y reproductivas heterogéneas. Por lo que, metodológicamente, se conciliaron los conceptos de frontera y región ya que en ambos se reconocen y se desprenden rasgos de carácter societario y económico, que implican intercambios de tipo material y humano. La relación entre la región fronteriza y el Estado central encubrieron historias entrelazadas. Esta se vuelve "un área de interrelación dinámica entre sociedades distintas, una frontera que de ninguna manera es un 'espacio vacío'; sino más bien un espacio que intenta ser ocupado y que, a su vez, es recorrido y traspasado en forma intermitente" (Areces, 1999, p. 26).

En otros términos, las líneas imaginarias que se trazan por el Estado no son fijas y, en la realidad cotidiana, son permanentemente rebasadas de forma tal que se configura un abanico de vínculos interétnicos. Oponiéndose al objetivo de definición territorial del Estado nación; queda delimitado el espacio que debió ocupar y defender, desde una perspectiva que lo considera más que como un límite (entre nación/desierto, productivo/improductivo o tradicional/moderno) (Trinchero, 2007). En este sentido, se debe entender a la frontera como una noción espacio-territorial ya que "se trata de la institucionalización de los límites territoriales del Estado al cual se dice que pertenece" (Areces, 2009, p. 306).

Por lo que resulta central destacar una característica nuclear: su permeabilidad. Esta permeabilidad transforma un espacio geográfico en las fronteras étnico-culturales, de modo que:

Estas pueden estar unas veces muy bien definidas y otras no alcanzan a diferenciarse, las pautas pueden ser terminantes y sencillas o bien tortuosas y complejas, y esta riqueza de diferenciación generalmente no coincide y, de hecho, no puede hacerlo ni con los límites de las unidades políticas ni con la voluntad (Areces, 1999, p. 26).

Este fenómeno no fue simbólico sino que se ubica en una región histórica, compuesta por el medio geográfico y sus recursos, las actividades productivas y las relaciones con el mercado, la dinámica demográfica, los núcleos de poder, la identidad y la colectividad expresada a través de los matrimonios y la identificación étnica.

Al enfocar la frontera como una institución dinámica, los investigadores locales (Areces, 1999, 2009; Banzato, 2009; Banzato y Lanteri, 2007; Iñigo, 1989; Rocchietti, 2008; Trinchero, 2000, 2007) tienen en cuenta los vínculos dados entre diferentes tipos de fronteras con las sociedades circundantes que han definido su propio espacio. Se rescata 
la construcción histórico-social de este espacio y las relaciones que se establecen entre las sociedades que convivieron y, al mismo tiempo, compitieron por el mismo lugar.

Las tierras, que para el Estado, son necesariamente urgente poblar, se denominan desierto. "La interioridad del desierto consiste simultáneamente en referencia geográfica, en lugar imaginario (para los blancos), en antípoda concreta, «campañas» que vienen a redimirlo de su alteridad, en vacía de clandestinidad cultural" (Rocchietti, 2008, p. 42). Por lo que la frontera, remite a una institución cuya duración pone en juego el nuevo plano social, político y cultural; esta institución se vuelve anacrónica e inútil desde el momento en que Argentina ingresa al mercado mundial y asociada a ella, la Provincia de Santa Fe.

\section{Frontera de colonización, una propuesta de análisis}

Alexandra Colony se desarrolla en un contexto de frontera de colonización (Dosztal, 2013; Trinchero, 2007) por ser una colonia agrícola sumergida en un ambiente geográfico y socialmente montaraz, lejano y desolador. Esta frontera ocupa un territorio "inhóspito", "bárbaro" contrapuesto al espacio "civilizado" que la sociedad hegemónica dominaba, aunque codiciado por los potenciales recursos que posee.

Esta frontera de colonización es producto de la conjunción de los conceptos de borderline y frontier utilizados por Turner (1921), no aisladamente, sino como una interacción dialéctica en los procesos colonizadores. Se define, border line como la formación de límites políticos entre dos Estados nación y frontier, como indicador de frentes expansivos, principalmente estructuras agrarias (Trinchero, 2007). De este modo, la frontera es un espacio social de violencia institucionalmente avalada que se conforma históricamente, en donde se articulaban relaciones económicas y políticas entre sociedades plurilingües y pluriculturales.

La Frontera poseía rostros complementarios: ella misma como organización militar y demográfica, es uno. El otro, era la Tierra Adentro, fuera del control político como cultural. La línea militar demarcaba el fin de la vigencia de las leyes españolas y, después, independientes. La Tierra Adentro describía el misterio de lo ignoto - en sentido geográfico- y el dominio de la organización tribal, lo primitivo como alegoría de lo natural, la unidad fundante del primitivo como Buen y mal salvaje (Rocchietti, 2008, p. 34).

Esta conexión del concepto de border-line y frontier permite abordar la política de ocupación llevada adelante entre 1866-1904 como un bloque expansivo colonizador (frontier) tras la línea de fortines que brindaba seguridad a las poblaciones de migrantes; dejándolas expuestas a posibles enfrentamientos con las parcialidades indígenas que no habían sido reducidas (Dosztal, 2013). La representación de la Figura 1 muestra la ausencia de defensa oficial cercana al área planteada como frontera de colonización. 
Figura 1: Plano modificado extraído de Spota (2009)

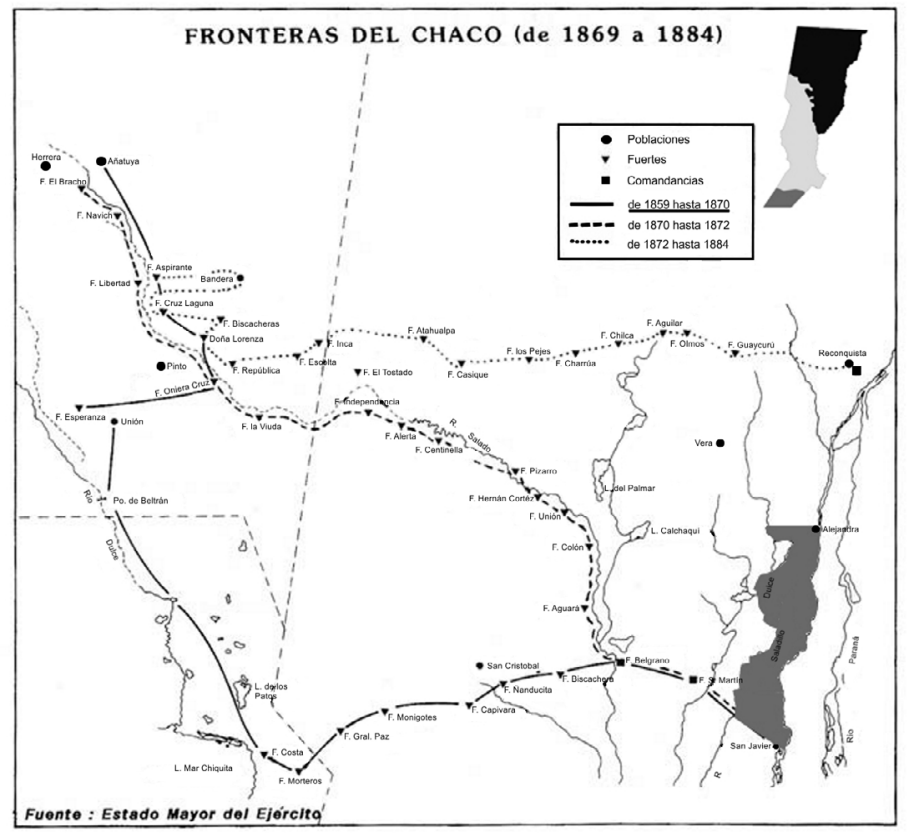

Nota: Para ubicar el área de la frontera de colonización (en gris) y su relación con las sucesivas líneas de fortines. En el periodo de 1859 a 1870 en el cual se fundaron las colonias agrícolas, la línea de fortines permaneció estática a la altura del pueblo indígena de San Javier, por lo que la población de inmigrantes queda expuesta a situaciones de enfrentamientos con las poblaciones originarias que resistían la ocupación.

Empero la visión positiva que se tenía de esta región que rige entre la clase dirigente de las décadas 1860 y 1870 , prevalece por sobre la seguridad de los colonos y se continúa con el poblamiento a pesar de los acontecimientos que se van sucediendo. El especialista alemán Burmeister (1944), ${ }^{5}$ considera que la región pampeana no era apta para el desarrollo de los cultivos cerealeros, y en cambio, sí lo son las tierras aledañas al litoral. De igual modo, Urbano de Iriondo (1876) lo ratificó afirmando que al norte de la capital provincial se encuentran los suelos apropiados para dicha actividad productiva: "allí donde el Creador se ostenta magnífico y bello [...] por las inapreciables riquezas que ha derramado con profusión en esa tierra verdaderamente privilegiada" (Iriondo, 1876, p.153). Fue tal el impacto de estos estudios que la colonización iniciada al oeste de la ciudad de Santa Fe se continúa hacia el norte. Los campos cubiertos de vegetación frondosa y los montes maravillan a quien se enfrentan a ellos:

Mis compañeros, la mayor parte agricultores de diferentes partes de los Estados Unidos, estuvieron unánimes en declarar que nunca han visto una estension [sic] tan grande de tierra tan uniformemente feráz [sic] como los terrenos del Paraná entre San Javier y el Rey, tomados en relación con su capacidad para la agricultura y el pastoreo (Perkins, 1867 , p. 20). ${ }^{6}$

\footnotetext{
${ }^{5}$ Hermann Burmeister, científico alemán quien tras realizar expediciones para estudiar la fauna, flora, geología y paleontología de varios países de Sudamérica publicó Viaje por los Estados del Plata con referencia especial a la constitución física y al estado de la cultura en la República Argentina: realizado en los años 1857, 1858, 1859 y 1860, en el año de 1944.

${ }^{6}$ Cita extraída del informe que realiza Williams Perkins tras el relevamiento y reconocimiento que realizó de los terrenos fiscales entre San Javier y el arroyo del Rey bajo las directivas del gobernador de la Provincia, Nicasio Oroño (1864-1868), para una futura mensura y venta del territorio.
} 
Dos hombres de la llamada generación del 37, futuros presidentes de la Nación, Bartolomé Mitre (1862-1868) y Domingo Faustino Sarmiento (1868-1874) coinciden en plantear que el espacio fronterizo estaba vacío, ${ }^{7}$ pero no de recursos, sino de civilización. Este espacio "vacío" es llenado con una persistente inmigración europea y norteamericana, que conforma una identidad fronteriza. Ambos, proyectan en el proceso colonizador la proeza de los migrantes ${ }^{8}$ de diferentes orígenes que al ocupar esas tierras libres, transformarían el paisaje natural y humano, coadyuvando a conformar la anhelada idiosincrasia nacional con el objetivo de integrar frontera-desierto, una de las rémoras que había que eliminar para encauzar la formación del incipiente Estado nación.

El asentamiento de esta colonización particular es valorado y apoyado por el gobierno de la Provincia de Santa Fe, afín a los lineamientos de la política nacional de colonización y, en consonancia, es vista como la puerta a la colonización espontánea de la región. De esta manera, se produce una serie de contratos entre el gobierno provincial, colonos independientes y compañías colonizadoras, estableciendo las condiciones para el asentamiento de inmigrantes tras la línea de frontera.

La frontera, por ende, se constituye en un espacio geográfico-histórico; en él se articulan relaciones económicas, sociales y políticas opuestas. En ese escenario civilización y barbarie se encuentran contradictoriamente para desenvolver sus propios proyectos de existencia social y cultural (Rocchietti, 2008). En este espacio donde se construye una nueva identidad convirtiendo en argentinos a los inmigrantes de diferentes orígenes y, a Argentina, en su patria. Estas tierras libres de rentas constituyen el motor de movilidad social, el cual no es posible en Europa (Turner, 1921). Estos pioneros transforman el espacio al instaurar un nuevo sistema social, cultural y geográfico; es decir, lo incorporan a una sociedad de clases. La dinámica social que se imprime en la frontera del Norte santafesino combina el establecimiento de colonias y la supervivencia en el territorio, al mismo tiempo que forja el carácter y las instituciones democráticas regentes en el resto del territorio controlado por el Estado.

En este contexto, la cuestión indígena es un problema urgente a resolver y se plantea un tratamiento en tres etapas. En la primera, desde 1854 a 1885 , la estrategia (militar y política) es defensiva-ofensiva; en la segunda, desde 1885 a 1911, se da un proceso de sometimiento y colonización y, finalmente, en la tercera, que comprende varios niveles de discusión política, entre 1904 a 1911 y entre ese año a 1921, se intenta una política de reparación (Rocchietti, 2008).

La época defensiva-ofensiva comprende el trazado metódico de la línea, es decir, la intervención directa y sistemática de las fuerzas militares estatales en la construcción de la frontera, la protección de bienes y vidas y el rescate de los cautivos (por su condición de argentinos). Se proveen fondos para estabilizarla, se ocupan áreas consideradas

\footnotetext{
${ }^{7}$ Esta percepción no tenía relación directa con la realidad puesto que en estos territorios habitaban parcialidades de mocovíes y abipones, algunas de las cuales fueron reducidas y sometidas mientras que otras resistieron aunque las continuas campañas militares los confinaron al monte más septentrional de la Argentina ubicados en la actual provincia del Chaco.

${ }^{8}$ Es así como el Coronel Juan F. Czetz le informa al presidente Sarmiento el valor de las colonias santafesinas a las puertas del Chaco (Dosztal, 2013):

Revelan en sus instrumentos de agricultura el bienestar de sus habitantes, condiciones que no alcanzan las poblaciones rurales de Europa. California o la Californiense es un pedazo de Kentucky o de Minnessota, por el genio yanqui que la anima por el rifle con el indio que va al del arado. Ni la guarnición de frontera llega hasta donde han llegado los colonos. Al Norte tienen el misterioso Chaco delante de sus ojos (Czetz citado en Tourn 2001, p. 27).
} 
estratégicas, se exploran otras (especialmente los ríos estimados como fronteras naturales con los indios) y se fundan pueblos.

El dominio es operado por el ejército, que como corporación militar (Trinchero, 2007), comienza a representar un rol múltiple y hegemónico comprometiéndose a otorgar estabilidad a la frontera.

El proceso de sometimiento y colonización se lleva adelante a través de la expropiación de las condiciones materiales de existencia de los indígenas y se instrumenta el monopolio de la fuerza física para lograr construir una clase trabajadora coherente al sistema productivo que se estaba implementando (Iñigo, 1984).

La integración de los indígenas en la propia sociedad, se da solo a condición de que se incorporasen a la vida civilizada, asumiendo forzosamente sus usos, formas, reglas y moral como asalariados precarizados por estar impedidos de constituirse como fuerza de trabajo permanente. "Tal objetivo implicaba anular la organización tribal de los aborígenes, borrar sus costumbres e incluso sus lenguas, escolarizar a sus hijos y convertirles, en general, en trabajadores productivos, como precio ineludible para concederles derechos de ciudadanía” (Quijada, 2000, p. 70).

En la conquista del Chaco santafesino, ${ }^{9}$ las iniciativas del gobierno provincial se ven reforzadas por los esfuerzos privados de colonos para expulsar a los pueblos de indios, para lo cual, el mismo gobierno, no deja de contribuir con insumos para la realización de las expediciones al "desierto". ${ }^{10}$ Con estas, se busca recuperar ganado y cautivos, depredaciones que son vistas por los colonos como ataques a su propiedad, entendiendo que de esa manera se estaba haciendo justicia. Estas políticas de avance de la civilización y el progreso - en manos de inmigrantes de diferentes orígenes que se unen frente a un otro extraño-, permiten al Estado formar un cordón defensivo y expansivo que se define como frontera de colonización.

\section{La frontera de colonización en el norte santafesino}

La frontera de colonización que se analiza aquí encuentra sus límites naturales en los ríos Saladillo Dulce y Amargo y San Javier, entre el río Paraná y el Gran Chaco, siendo terrenos fiscales que abarcan desde el pueblo de San Javier hasta el arroyo el Rey, con una extensión de $180 \mathrm{~km}$. Esta frontera se encuentra ubicada entre dos antiguas reducciones jesuíticas: una de mocovíes al sur y otra de abipones al norte. El área denominada Pájaro Blanco - topónimo otorgado por la abundante presencia en sus montes de garzas aves de cuerpo blanco y pico negro-, a $90 \mathrm{~km}$ de distancia de ambos extremos, conforma el sector en el que se extienden los campos de mejor calidad para la producción agrícola, donde a los paisanos reducidos les es permitido cazar y donde "ya no había peligro" (Perkins, 1867, p. 49) (Figura 2).

\footnotetext{
${ }^{9}$ El Chaco santafesino comprende un área triangular de aproximadamente $54000 \mathrm{~km}^{2}$ que forma el extremo sudeste de la gran llanura chaqueña, se desarrolla desde el paralelo $28^{\circ} 03^{\prime} 33^{\prime \prime}$ al $31^{\circ} 38^{\prime 2} 22^{\prime \prime}$ Sur. Abarcando completamente los departamentos: 9 de Julio, Vera, General Obligado, San Justo, San Javier, Garay, gran parte del departamento Capital y parcialmente los departamentos San Cristóbal, Castellanos y Las Colonias, llegando hasta la ciudad de Santa Fe (Iriondo, 2007).

${ }^{10}$ Con el concepto desierto utilizado por la clase dirigente del periodo, se hace referencia a las vastas zonas no colonizadas del interior del país, es decir, a las regiones más allá de las fronteras.
} 
Figura 2: Ubicación geográfica e histórica de la frontera de colonización (Perkins 1867)

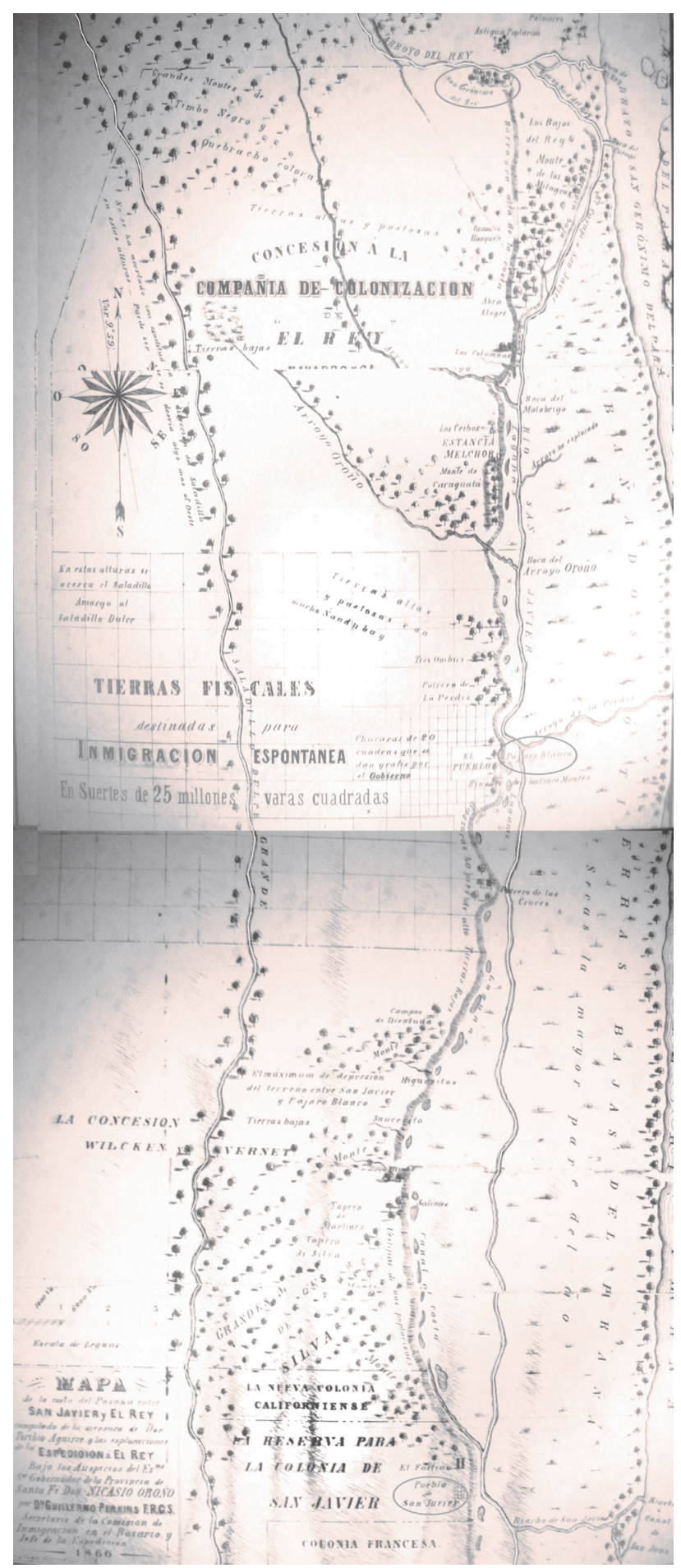

Nota: En el mapa se identifican los límites formados por dos antiguas reducciones jesuíticas, al sur de indígenas mocovíes y al norte de abipones, y el área de mejor calidad ambiental donde se establecerá Alexandra Colony. 
A través de una revisión de los acontecimientos que viven los primeros pobladores europeos y norteamericanos de esta región, se puede ratificar que tácitamente el área de estos asentamientos era una zona de paz donde los distintos grupos indígenas montaraces y reducidos- podían cazar sin restricciones, pero en este acuerdo no incluye la nueva población inmigrante, por lo que sus consecuencias fueron narradas en informes oficiales, epístolas, periódicos y diarios de campo.

En esta área se concreta la fundación sucesiva de colonias que se establecieron antes que estas tierras fuesen incorporadas al territorio controlado por el gobierno provincial. Este proceso formó parte de una unidad de organización social del espacio, que propone una nueva forma de poblamiento, nuevas estructuras económicas y sociales, nuevas formas de poder y, en suma, un nuevo sistema de valores (Areces, 1999). Esta nueva tenencia de la tierra, es decir, las leyes aplicadas por el Estado respecto a la venta, alquiler, arrendamiento o reparto de tierras fiscales, otorga otro carácter paisajístico, social y económico a la región.

Esta misma región cuenta con una endeble protección oficial ya que los fortines, escasamente pertrechados y erigidos a lo largo del territorio ocupado por población foránea, no generan las condiciones requeridas para lograr el control territorial y disciplinario de la población indígena. Esta situación lleva a que los miembros de la administración y colonos se defendiesen de los ataques, por la ocupación de sus territorios, de la resistencia indígena. Este tipo de enfrentamientos, que por periodos se daban con gran frecuencia, desarrolla en los grupos sociales recursos que les permitieron superar este tipo de situaciones adversas (Schiera, 2005). En este ambiente, por ejemplo los colonos salieron en auxilio de la comandancia del fortín, más de una vez, que se encontraba entre California y San Javier. En una oportunidad el mismo se hallaba rodeado por el jefe y un grupo de indios que reclamaban por la acusación injusta contra dos de sus hombres por haber matado a unos visitantes. En un primer momento, el californiano William T. Moore optó por mediar entre ambos grupos, pero al no lograrlo, se llevó adelante un enfrentamiento que concluyó con la muerte de varios indígenas y la huida al monte de la mayor parte del grupo (Vogel, 1946).

El objetivo de estos ataques, generalmente, es el ganado vacuno y caballar, muchas veces las muertes son involuntarias. Por ejemplo, Colonia California sufre sucesivos hurtos; mientras que sus vecinos de Colonia Eloisa viven tranquilamente trabajando la tierra: huertos, viñedos y cultivos, hasta que un año después al combinar la producción con la ganadería, sufren su primer ataque en mayo de 1871, en el que mueren tres colonos y es raptado un niño (Vogel, 1946).

Por su parte, a dos meses de la llegada a tierras santafesinas, tras gestionar la mensura del terreno previa a la llegada de los inmigrantes (que comienza pero no concluye), el agrimensor Edwin A. Hudson, expresa: "vengo a renunciar gustoso al cargo que se me había encomendado para practicar dicha medición dando á $[s i c]$ esos Señores las gracias mas [sic] expresivas por haberme exonerado de un compromiso tan desagradable" (Hudson, 1870, p. 12), así, queda inconclusa, producto de los sucesivos ataques de los grupos indígenas de la región, que en el periodo más intenso, llegan a ser diarios según detalla Andrew Weguelin en una carta de enero de 1871: "en vista de todo ello he llegado a la conclusión de que como sería imposible hacer cualquier trabajo en forma segura con no menos de cien hombres, deberíamos abandonar la colonia y enviar a casa todos los hombres" (Weguelin, 1871). ${ }^{11}$ La misma pudo ser concluida por el agrimensor Cayetano

11 La colección epistolar citada en este apartado y a la largo de la obra forma parte del archivo personal de Guido A. Tourn Pavillon. 
Livi, quien mensuró, deslindó y amojonó el total del campo en un periodo que va desde marzo a junio de 1871.

Dichos eventos se sucedieron, incluso, tras el corrimiento de la frontera a la altura de la Reconquista, en 1872. La repuesta a los mismos se encuentra registrada en diversos documentos, destacándose las relaciones enviadas al gobierno que describen el día a día de las expediciones contra los indios montaraces dirigidas por W. T. Moore. La primera se realiza tras la invasión sufrida en Colonia Romang, que se ubica al norte de Alexandra Colony, a fines de junio de 1875 . El poblado es saqueado e incendiado, vecinos mueren durante el ataque y dos niños son llevados cautivos.

La expedición cuenta con el apoyo del gobierno provincial presidido por Servando Bayo y, el 3 de julio de 1875, 25 hombres voluntarios de las colonias California, Alejandra y Romang, se adentran al monte con el fin de eliminar al enemigo en común.

Producto de la falta de agua, la expedición se ve truncada y los expedicionarios regresan con cierto saldo a favor:

17 indios muertos cuyos estamos seguros y un gran número que morirán sin duda de sus heridas; tres muchachos hechos prisioneros; 17 ovejas todas comidas en el camino, 3 vacas lecheras traídas de Malabrigo; 26 caballos vueltos a tomar. Una gran cantidad de curiosidades fueron también traídas y entre otras huesos de dedos cuyos servían como botones. En el pueblito de los indios, encontramos yerba, café molido, azúcar y también una gran cantidad de utensilios de cocina en fonta y fierro batido, etc. A según la opinión de nuestro jefe Don Guillermo Moore, esto proviene de la existencia de relaciones amigables con los indios del Rey (Grobet, 1875, p. 3).

En septiembre del mismo año se realiza una nueva incursión con suministros provistos por el gobierno, se extiende desde el jueves 2 de septiembre al martes 5 de octubre, el día a día fue relatado por Juan Grobet en un diario de marcha. Durante la misma se ataca una toldería y dieron muerte a tres indios, un grupo de mujeres y niños fueron capturados y llevados al campamento. Las cautivas indican que cerca estaban los tobas con mucha hacienda, pero como estos nunca atacan las colonias deciden no llevar adelante ninguna acción. Los atracos siempre se adjudican a Juan Gregorio, antiguo cacique de los indígenas de San Javier, quién se escapa de Martín García.

A pocos días de su regreso, la desgracia vuelve a teñir a las colonias. El hijo del capitán Moore, William Henry Moore juez de paz de Alexandra Colony y su director Arthur L. Powys, mueren en una emboscada. Ellos salen junto al peón Pío García y James R. Holman en persecución de un grupo de indios que habían robado caballos de los establos de la administración, pero son sorprendidos por un grupo que los superaba en cantidad (Tourn, 2001). Las repercusiones no se hicieron esperar y otra expedición autorizada se lleva a cabo en noviembre, el procedimiento fue el mismo de siempre pero esta vez se da muerte a una mayor cantidad de indios y se capturan 61 prisioneros.

Tras la muerte de su hijo, William T. Moore, retorna a los Estados Unidos en julio de 1877, mientras que su hermano Benjamín L. Moore, continúa liderando algunas expediciones punitivas para poner coto a los ataques indígenas, que se hacían más esporádicos hacia fines de la década gracias al avance de la línea de fortines hacia el norte y el afianzamiento de la Reconquista como frente de defensa y, finalmente, la conquista militar del Chaco emprendida por el gobierno nacional en 1884 (Maffucci, 2007).

Estas campañas dirigidas por colonos, son bien vistas por los gobernantes pero repudiadas por el cuerpo de oficiales del Estado Mayor, encargados de proteger la frontera, ya que ven desacreditado su trabajo. Sin embargo, la deserción de las tropas es 
una realidad entre 1872 y 1884 , producto de la constante dificultad económica que se tradujo en la imposibilidad de movilización para recorrer la línea de fortines y transmitir la información acerca de posibles ataques indígenas o de avance más allá del paralelo 28. Su misión encomendada de avance a través de la ocupación sucesiva del territorio no pudo ser afrontada y: "encontró una fuerza subsidiaria en iniciativas privadas llevadas a cabo por colonos europeos que realizaban incursiones armadas contra poblaciones aborígenes" (Brac, 2009, p. 77).

De este modo, los conceptos de ataque y defensa se desdibujan de acuerdo a qué lado de la frontera se ubican los protagonistas. En las resistencias que coexistieron, aproximadamente por medio siglo, se enfrentaron dos proyectos de país que gracias a las diferentes intervenciones oficiales permitieron que triunfara la civilización, erradicando las diferentes parcialidades indígenas de las tierras donde habían nacido y vivido por generaciones.

La Tabla 1, sintetiza el carácter resiliente que envuelve a los enfrentamientos desde 1866 — año de fundación de Colonia California— a 1904, fecha de la última sublevación mocoví inmortalizada en la historia como "el último malón" (Tabla 1). En la misma hay tres protagonistas: el Estado y sus instituciones, los colonos y los grupos indígenas. Este carácter resiliente se observa tanto en el segundo como en el tercer componente, mientras que el Estado se presenta como garante y promovedor de una política expansionista que promocionó la producción de capital para exportación por encima de la población originaria y su cultura, buscando efectivamente darle un cierre a la cuestión indígena.

Tabla 1: Testimonio del carácter resiliente en el Chaco Austral santafesino diagramada de acuerdo al rol de cada una de las parcialidades enfrentadas

\begin{tabular}{|c|c|c|c|c|}
\hline Fecha & Actores & Acontecimientos & Consecuencias & $\begin{array}{c}\text { Fuente } \\
\text { documental }\end{array}$ \\
\hline Enero 1866 & $\begin{array}{l}\text { Gobernador N. } \\
\text { Oroño }\end{array}$ & $\begin{array}{l}\text { Ordena al Teniente } \\
\text { Coronel M. Olme- } \\
\text { do a combatir a } \\
\text { los indígenas no } \\
\text { reducidos. }\end{array}$ & $\begin{array}{l}74 \text { indígenas } \\
\text { muertos - cacique } \\
\text { P. Marcona-, } 109 \\
\text { prisioneros y rescate } \\
\text { de siete cautivos. }\end{array}$ & $\begin{array}{l}\text { Maffucci, } \\
2007\end{array}$ \\
\hline Agosto 1866 & $\begin{array}{l}\text { Gobierno } \\
\text { provincial e } \\
\text { inmigrantes } \\
\text { estadouniden- } \\
\text { ses }\end{array}$ & $\begin{array}{l}\text { Fundación de } \\
\text { Colonia California } \\
\text { a } 5 \mathrm{~km} \text { al norte del } \\
\text { pueblo San Javier. }\end{array}$ & $\begin{array}{l}\text { Primer asentamiento } \\
\text { de inmigrantes tras la } \\
\text { frontera norte de la } \\
\text { Provincia de Santa Fe. }\end{array}$ & $\begin{array}{l}\text { Wilcken, } \\
1873\end{array}$ \\
\hline Diciembre 1866 & $\begin{array}{l}\text { Teniente } \\
\text { Coronel M. } \\
\text { Olmedo y } \\
\text { huestes }\end{array}$ & $\begin{array}{l}\text { Ataque a } \\
\text { campamentos } \\
\text { indígenas en monte } \\
\text { a la vera del río San } \\
\text { Javier. }\end{array}$ & $\begin{array}{l}\text { Tres indígenas } \\
\text { muertos, rescate de } \\
\text { tres cautivos y de } 15 \\
\text { caballos. }\end{array}$ & $\begin{array}{l}\text { Maffucci, } \\
2007\end{array}$ \\
\hline 1867 & Indígenas & $\begin{array}{l}\text { Sucesivos robos de } \\
\text { ganado vacuno y } \\
\text { caballar en Colonia } \\
\text { California. }\end{array}$ & $\begin{array}{l}\text { Compra de armas } \\
\text { por parte de los } \\
\text { colonos. }\end{array}$ & $\begin{array}{l}\text { Vogel, } \\
1946\end{array}$ \\
\hline 1867 & $\begin{array}{l}\text { Gobierno } \\
\text { provincial e } \\
\text { inmigrantes } \\
\text { galeses }\end{array}$ & $\begin{array}{l}\text { Fundación de } \\
\text { Colonia Galesa en } \\
\text { el límite norte de } \\
\text { Colonia California. }\end{array}$ & $\begin{array}{l}\text { Segundo asenta- } \\
\text { miento de inmigran- } \\
\text { tes tras la frontera } \\
\text { norte de la Provincia } \\
\text { de Santa Fe. }\end{array}$ & $\begin{array}{l}\text { Wilcken, } \\
1873\end{array}$ \\
\hline
\end{tabular}




\begin{tabular}{|c|c|c|c|c|}
\hline Enero 1869 & Indígenas & $\begin{array}{l}\text { Robo de caballos en } \\
\text { Colonia California. }\end{array}$ & $\begin{array}{l}\text { Reclamo por mayor } \\
\text { protección ante las } \\
\text { autoridades provin- } \\
\text { ciales por parte del } \\
\text { director de la colonia, } \\
\text { A. McLean. }\end{array}$ & $\begin{array}{l}\text { Tourn, } \\
2001\end{array}$ \\
\hline Enero 1869 & Indígenas & $\begin{array}{l}\text { Asalto en Colonia } \\
\text { Eloísa. }\end{array}$ & $\begin{array}{l}\text { Muerte de colono } \\
\text { francés. }\end{array}$ & $\begin{array}{l}\text { Tourn, } \\
2001\end{array}$ \\
\hline 1869 & Colonos & $\begin{array}{l}\text { Persecución a indí- } \\
\text { genas no reducidos. }\end{array}$ & $\begin{array}{l}\text { Sin resultados evi- } \\
\text { dentes. }\end{array}$ & $\begin{array}{l}\text { Tourn, } \\
2001\end{array}$ \\
\hline Abril 1869 & $\begin{array}{l}\text { Gobierno } \\
\text { provincial y } \\
\text { la empresa } \\
\text { colonizadora } \\
\text { Warnes, Her- } \\
\text { bet \& Cia. }\end{array}$ & $\begin{array}{l}\text { Fundación de } \\
\text { Colonia Eloísa en } \\
\text { el límite norte de } \\
\text { Colonia Galesa a } \\
60 \text { km de Colonia } \\
\text { California. }\end{array}$ & $\begin{array}{l}\text { Tercer asentamiento } \\
\text { de inmigrantes tras } \\
\text { la frontera norte de } \\
\text { la Provincia de Santa } \\
\text { Fe. }\end{array}$ & $\begin{array}{l}\text { Wilcken, } \\
1873 \mathrm{y} \\
\text { Vogel, } 1946\end{array}$ \\
\hline Abril 1870 & Indígenas & $\begin{array}{l}\text { Emboscada a } \\
\text { colonos de Colonia } \\
\text { Galesa. }\end{array}$ & $\begin{array}{l}\text { Mueren los colonos } \\
\text { W. Wasp y E. Burrel. }\end{array}$ & $\begin{array}{l}\text { Tourn, } \\
2001\end{array}$ \\
\hline Octubre 1870 & $\begin{array}{l}\text { Gobierno } \\
\text { provincial y } \\
\text { la empresa } \\
\text { colonizadora } \\
\text { Thomson, } \\
\text { Bonar \& Cia. }\end{array}$ & $\begin{array}{l}\text { Fundación de } \\
\text { Alexandra Colony a } \\
90 \mathrm{~km} \text { al norte del } \\
\text { límite fronterizo. }\end{array}$ & $\begin{array}{l}\text { Cuarto asentamiento } \\
\text { de inmigrantes tras } \\
\text { la frontera norte de } \\
\text { la Provincia de } \\
\text { Santa Fe. }\end{array}$ & $\begin{array}{l}\text { Wilcken, } \\
1873\end{array}$ \\
\hline $\begin{array}{l}\text { Noviembre } \\
\text { y diciembre } 1870\end{array}$ & Indígenas & $\begin{array}{l}\text { Asalto a las recien- } \\
\text { tes instalaciones in- } \\
\text { glesas en Alexandra } \\
\text { Colony. }\end{array}$ & $\begin{array}{l}\text { Preocupación y } \\
\text { cuestionamiento de } \\
\text { la continuidad del } \\
\text { proyecto colonizador. }\end{array}$ & $\begin{array}{l}\text { Weguelin, } \\
1871\end{array}$ \\
\hline Mayo 1871 & Indígenas & $\begin{array}{l}\text { Asalto en Colonia } \\
\text { Eloísa. }\end{array}$ & $\begin{array}{l}\text { Tres colonos muer- } \\
\text { tos - L. Henriet-, } \\
\text { violación de una mu- } \\
\text { jer, rapto de su hijo y } \\
\text { robo de } 30 \text { caballos } \\
\text { y } 500 \text { cabezas de } \\
\text { ganado vacuno. }\end{array}$ & $\begin{array}{l}\text { Vogel, } \\
1946\end{array}$ \\
\hline Mayo 1871 & $\begin{array}{l}\text { Colonos Colo- } \\
\text { nia California }\end{array}$ & $\begin{array}{l}\text { Persecución en } \\
\text { busca de indígenas } \\
\text { que atacaron a los } \\
\text { colonos de Eloísa } \\
\text { dirigida por W. } \\
\text { Moore. }\end{array}$ & $\begin{array}{l}\text { Tres indígenas muer- } \\
\text { tos y recuperación } \\
\text { del niño capturado } \\
\text { días antes. }\end{array}$ & $\begin{array}{l}\text { Vogel, } \\
1946\end{array}$ \\
\hline Octubre 1871 & Indígenas & $\begin{array}{l}\text { Asalto instalaciones } \\
\text { inglesas en Alexan- } \\
\text { dra Colony. }\end{array}$ & $\begin{array}{l}\text { Muere el fundador } \\
\text { de la colonia A. We- } \\
\text { guelin y E. Rostán. } \\
\text { Robo de la totalidad } \\
\text { del ganado vacuno y } \\
\text { caballar. }\end{array}$ & $\begin{array}{l}\text { "The } \\
\text { Chaco } \\
\text { Indians", } \\
1871\end{array}$ \\
\hline Octubre 1871 & $\begin{array}{l}\text { Ministro Inglés } \\
\text { H. McDonell }\end{array}$ & $\begin{array}{l}\text { Reclamo a autorida- } \\
\text { des nacionales por } \\
\text { las muertes sucedi- } \\
\text { das en Alexandra } \\
\text { Colony. }\end{array}$ & $\begin{array}{l}\text { Corrimiento provi- } \\
\text { sorio de la línea de } \\
\text { frontera al límite } \\
\text { norte de la colonia. }\end{array}$ & $\begin{array}{l}\text { Tourn, } \\
1999\end{array}$ \\
\hline
\end{tabular}




\begin{tabular}{|c|c|c|c|c|}
\hline Diciembre 1871 & Indígenas & $\begin{array}{l}\text { Emboscada al fortín } \\
\text { ubicado entre San } \\
\text { Javier y Colonia Ca- } \\
\text { lifornia y auxilia a } \\
\text { la comandancia por } \\
\text { parte de E. Moore. }\end{array}$ & $\begin{array}{l}\text { Muerte y huida de va- } \\
\text { rios indígenas. }\end{array}$ & $\begin{array}{l}\text { Vogel, } \\
1946\end{array}$ \\
\hline Marzo 1872 & $\begin{array}{l}\text { Gobierno } \\
\text { Nacional }\end{array}$ & $\begin{array}{l}\text { Corrimiento de la } \\
\text { línea de fortines a } \\
\text { la altura de la actual } \\
\text { localidad de Recon- } \\
\text { quista a } 90 \mathrm{~km} \text { de } \\
\text { Alexandra Colony. }\end{array}$ & $\begin{array}{l}\text { Cambio en la distri- } \\
\text { bución territorial, } \\
\text { las cuatro colonias } \\
\text { se ubican definiti- } \\
\text { vamente dentro del } \\
\text { territorio controlado } \\
\text { por el gobierno pro- } \\
\text { vincial. }\end{array}$ & $\begin{array}{l}\text { Tourn, } \\
2001\end{array}$ \\
\hline Septiembre 1872 & Indígenas & $\begin{array}{l}\text { Asalto a inmigran- } \\
\text { tes valdenses recién } \\
\text { llegados a Alexan- } \\
\text { dra Colony. }\end{array}$ & $\begin{array}{l}\text { Muerte del conduc- } \\
\text { tor de la carreta, Ro- } \\
\text { gers. }\end{array}$ & $\begin{array}{l}\text { Tourn, } \\
2001\end{array}$ \\
\hline Junio 1875 & Indígenas & $\begin{array}{l}\text { Asalto en Colonia } \\
\text { Malabrigo ubicada } \\
\text { tras el límite nor- } \\
\text { te de Alexandra } \\
\text { Colony, actual Ro- } \\
\text { mang. }\end{array}$ & $\begin{array}{l}\text { Muerte del matrimo- } \\
\text { nio M. Brüe y M. Ka- } \\
\text { ppeler, secuestro de } \\
\text { sus dos hijos y robo } \\
\text { de } 100 \text { yeguas. }\end{array}$ & $\begin{array}{l}\text { Tourn, } \\
2001\end{array}$ \\
\hline Julio 1875 & $\begin{array}{l}\text { Colonos de } \\
\text { Colonia Cali- } \\
\text { fornia }\end{array}$ & $\begin{array}{l}\text { Persecución en } \\
\text { tierras de indígenas } \\
\text { no reducidos, en } \\
\text { busca de los cauti- } \\
\text { vos y el ganado. }\end{array}$ & $\begin{array}{l}17 \text { indígenas muer- } \\
\text { tos y tres prisioneros. }\end{array}$ & $\begin{array}{l}\text { Grobet, } \\
1875\end{array}$ \\
\hline Septiembre 1875 & $\begin{array}{l}\text { Colonos de to- } \\
\text { das las colonias } \\
\text { de la región }\end{array}$ & $\begin{array}{l}\text { Persecución en tie- } \\
\text { rras de indígenas no } \\
\text { reducidos, en busca } \\
\text { de los cautivos y el } \\
\text { ganado. }\end{array}$ & $\begin{array}{l}\text { Tres indígenas muer- } \\
\text { tos y toma de prisio- } \\
\text { neros. }\end{array}$ & $\begin{array}{l}\text { Grobet, } \\
1875\end{array}$ \\
\hline Septiembre 1875 & Indígenas & $\begin{array}{l}\text { Robo de caballos y } \\
\text { emboscada a colo- } \\
\text { nos de Alexandra } \\
\text { Colony. }\end{array}$ & $\begin{array}{l}\text { Muerte de W. Moore } \\
\text { (hijo) y del adminis- } \\
\text { trador de la colonia } \\
\text { A. Powys. }\end{array}$ & $\begin{array}{l}\text { Tourn, } \\
2001\end{array}$ \\
\hline Noviembre 1875 & $\begin{array}{l}\text { Colonos de to- } \\
\text { das las colonias } \\
\text { de la región. }\end{array}$ & $\begin{array}{l}\text { Persecución en tie- } \\
\text { rras de indígenas no } \\
\text { reducidos en repre- } \\
\text { salia por la muerte } \\
\text { de Moore y Powys. }\end{array}$ & $\begin{array}{l}\text { No contabilizada } \\
\text { la muerte de indí- } \\
\text { genas y toma de } 61 \\
\text { prisioneros. }\end{array}$ & $\begin{array}{l}\text { Grobet, } \\
1875\end{array}$ \\
\hline Diciembre 1876 & Indígenas & $\begin{array}{l}\text { Asalto al puesto de } \\
\text { S. Sager en Colonia } \\
\text { Romang. }\end{array}$ & $\begin{array}{l}\text { W. Moore persigue } \\
\text { a los indígenas y da } \\
\text { muerte a cinco de } \\
\text { ellos. }\end{array}$ & $\begin{array}{l}\text { Maffucci, } \\
2007\end{array}$ \\
\hline $\begin{array}{l}\text { Enero } \\
1877\end{array}$ & Indígenas & $\begin{array}{l}\text { Robo de ganado en } \\
\text { Alexandra Colony. }\end{array}$ & 40 yeguarizos. & $\begin{array}{l}\text { To u r n } \\
2001\end{array}$ \\
\hline Enero y febrero 1877 & Indígenas & $\begin{array}{l}\text { Robo en Colonia } \\
\text { Romang. }\end{array}$ & $\begin{array}{l}\text { Muere el colono } \\
\text { Juan Sager. }\end{array}$ & $\begin{array}{l}\text { To u r n } \\
2001\end{array}$ \\
\hline 1877 & $\begin{array}{l}\text { Gobierno } \\
\text { Nacional }\end{array}$ & $\begin{array}{l}\text { Establece doce for- } \\
\text { tines en las inme- } \\
\text { diaciones de Recon- } \\
\text { quista. }\end{array}$ & $\begin{array}{l}\text { Sometimiento de las } \\
\text { tribus de los caci- } \\
\text { ques: V. Cisterna, M. } \\
\text { Lanche, M. Villalba y } \\
\text { A. Carabayo. }\end{array}$ & $\begin{array}{l}\text { Tourn, } \\
2001\end{array}$ \\
\hline
\end{tabular}




\begin{tabular}{|c|c|c|c|c|c|}
\hline & 1884 & $\begin{array}{l}\text { Gobierno nacio- } \\
\text { nal } \\
\text { Gobierno } \\
\text { nacional } \\
\text { Indígenas }\end{array}$ & $\begin{array}{l}\text { Conquista del } \\
\text { Chaco. } \\
\text { Establecimiento } \\
\text { de la Reducción } \\
\text { de San Antonio de } \\
\text { Padua (actual San } \\
\text { Antonio de Obli- } \\
\text { gado) a } 170 \text { km al } \\
\text { norte de Alexandra } \\
\text { Colony. } \\
\text { Sublevación moco- } \\
\text { víes reducidos de } \\
\text { San Javier, conocida } \\
\text { como "el último } \\
\text { malón". }\end{array}$ & $\begin{array}{l}\text { Corrimiento de la } \\
\text { frontera del Chaco } \\
\text { Austral hasta el río } \\
\text { Bermejo. } \\
\text { Control de los } \\
\text { grupos indígenas } \\
\text { que hasta la fecha } \\
\text { no habían sido } \\
\text { reducidos. } \\
\\
\text { Subordinación } \\
\text { indígena. Fin de una } \\
\text { contienda secular en- } \\
\text { tre las poblaciones ori- } \\
\text { ginarias y los sucesivos } \\
\text { gobiernos provinciales } \\
\text { y nacionales. }\end{array}$ & $\begin{array}{l}\text { Alemán, } \\
1997\end{array}$ \\
\hline
\end{tabular}

La prolongación de la política de avance militar sobre el Chaco santafesino, como garantía de seguridad en la vida diaria de las colonias de la región, convierte hacia fines del siglo XIX a Alexandra Colony en un polo de atracción comercial y residencial para los habitantes de los asentamientos vecinos, cuyo progreso planificado no es posible por las condiciones señaladas y terminaron convirtiéndose en desolados parajes, testimonio de una política colonizadora truncada por la realidad misma de la región que es ignorada por los sucesivos gobiernos provinciales y nacionales.

Con los años, el área urbana de Alejandra — compuesta por catorce viviendas- se transformó en el centro de compra y venta de los ganaderos de la región. Lejos del progreso atribuido a sus tierras fértiles, abundante agua, montes y al capital invertido, Alexandra Colony no se convirtió en un proyecto modelo que, de ser imitado en la región, permitiese convertirla en un centro floreciente de civilización. La historiografía local la denominó "madre de colonias" (Tourn, 2001), ya que la dispersión de la población, tras su venta en 1885, le ofreció a los nuevos asentamientos que se desarrollaban a kilómetros de ella — como Florencia, Calchaquí, Reconquista en Santa Fe y colonia Valdense en Uruguay- individuos labradores con experiencia y conocimiento en el trabajo de la tierra.

\section{Palabras finales}

La sociedad de frontera al ser liminar, poseía una baja productividad; por lo que la expropiación de sus tierras a las sociedades originarias (para incorporarlas al territorio controlado por el Estado Nación y así fueran explotadas por manos de familias colonas de inmigrantes) permitió a la clase gobernante orientar el ingreso de Argentina hacia el sistema capitalista de producción.

Proceso del cual las colonias California, Galesa, Eloisa y Alexandra son testimonio, al sintetizar en ellas todos los adelantos y progresos descritos en la documentación histórica 
sin escatimar adjetivos calificativos. Las modificaciones en las costumbres en el trabajo, en la producción de alimentos y su consumo, transformaron las vastas y despobladas tierras de la Provincia de Santa Fe en un espacio europeizado.

La frontera norte de la Provincia de Santa Fe en la segunda mitad del siglo XIX, fue un espacio geográfico signado por la violencia donde se disputan intereses políticos, económicos y sociales. Entonces, el contexto en el que se desarrolla el proyecto colonizador Alexandra Colony fue de sucesivas contiendas e incertidumbres similares al de otras fronteras de la República Argentina, pero cuya mayor diferencia fue que la defensa del territorio estuvo a cargo de los colonos inmigrantes y no por miembros del ejército. Caracterizándose por su marcada militarización organizaron una fuerza paramilitar que reforzó la protección de una endeble frontera.

En síntesis, este abordaje de la historia regional demuestra su correspondencia directa con la historia provincial y nacional, y la historia local de cada una de estas colonias, supera la mera descripción de sucesos para dar paso a la construcción de identidades sociales en el territorio involucrado (Fernández, 2007), en cuyo contexto, el sentido de pertenencia puso en tensión las relaciones con el otro, compuesto por los pueblos de la familia lingüística guaycurú, parcialidades abipona y mocoví que poblaron con anterioridad la misma porción de tierra; vínculo negativo que destacaba la distintividad identitaria en un espacio y tiempo particulares.

$\mathrm{El}$ alambrado, las maquinarias agrícolas, la siembra de cereales y tabaco por parte de la nueva población rural en crecimiento, combatieron el desierto convirtiéndose en testimonio de la política expansionista y modernizadora instaurada desde mediados del siglo XIX. De este modo, "es la racionalidad burguesa la que construye un espacio finito, medible y real, ya que sólo estas características pueden permitir que aquello que se denomina espacio se puede parcelar, repartir, expropiar, vender, explotar, destruir" (Criado, 1993, p. 13). El monte se fue talando; las tierras, que parecían infinitas, se delimitaron con alambrado, las construcciones de ladrillos fueron emergiendo en el ambiente y lo convirtieron en un paisaje ruralizado con pautas de ocupación del espacio, relaciones sociales y formaciones socio-económicas que representaron un panorama dispar al anteriormente conocido por las poblaciones indígenas originarias que fueron confinadas, cada vez más, al norte del territorio provincial.

El carácter resiliente de los colonos les permitió sobrellevar el acontecer en una frontera de colonización signada por el sacrificio y la violencia. Aunque, a través de los años, los enfrentamientos armados se transformaron en atracos de ganado vacuno y caballar, los grupos humanos construyen entorno a ello su tiempo presente, ese presente que lo separa de su pasado en Europa y futuro, por lo que el análisis de los mismos se acerca a esa realidad que como parte de una cultura viva y en movimiento constante establecía relaciones sociales sostenidas en el tiempo y permite la subsistencia.

\section{Referencias}

Alemán, B. E. (1970). El problema del indio en la historia de Santa Fe, desde la evolución de Mayo hasta la organización nacional. En Historia de las instituciones de la provincia de Santa Fe (Tomos III, Libro I, Capítulo II, pp. 39-85). Santa Fe, Argentina: Imprenta Oficial, Comisión Redactora de la Historia de las Instituciones de la Provincia de Santa Fe.

Alemán, B. E. (1981). Contribución de Santa Fe a la conquista del desierto. Revista de la Junta Provincial de Estudios Históricos de Santa Fe, (LI), 99-114. 
Alemán, B. E. (1997). Santa Fe y sus aborígenes (2ª parte). Santa Fe, Argentina: Junta Provincial de Estudios Históricos.

Areces, N. R. (1999). Regiones y fronteras. Apuntes desde la Historia, Andes, (10), 17-31.

Areces, N. R. (2009). Paisaje fronterizo e historia en el Paraguay de los López. En E. Néspolo, M. Ramos y B. Goldwaser (Eds.), Signos en el tiempo y rastros en la tierra (Segunda época, Vol. III, pp. 305-328). Buenos Aires, Argentina: Biblos.

Banzato, G. (2009). La frontera del mercado de tierras durante la expansión de la frontera bonaerense. Chascomús y Junín, 1860-1890. Trabajos y Comunicaciones (35), 255277.

Banzato, G. y Lanteri, S. (2007). Forjando la frontera. Políticas públicas y estrategias privadas en el Río de la Plata, 1780-1860. Historia Agraria, (43), 435-458.

Benedetti, A. (2007). El debate sobre las fronteras en la Argentina. Estudios Socio-Territoriales, (6), 11-36.

Brac, M. (2009). La explotación forestal. Algunas consideraciones sobre procesos económicos y ocupación del espacio en el Chaco Santafesino. Cuadernos de Antropología, 5, 71-94.

Burmeister, H. (1944). Viaje por los Estados del Plata con referencia especial a la constitución física y al estado de cultura de la República Argentina: realizado en los años 1857, 1858, 1859 y 1960 (Vol. 1-3). Buenos Aires, Argentina: Unión germánica en la Argentina.

Criado, F. (1993). Límites y posibilidades de la arqueología del paisaje. SPAL Revista de Prehistoria y Arqueología, (2), 09-55.

Dosztal, I. (2010). Primeras intervenciones en el predio de La Casa de La Administración, sede de la colonización del norte santafesino, 1870, Alejandra, Santa Fe. Trabajo presentado en xvir Congreso Nacional de Arqueología Argentina, Mendoza, Argentina.

Dosztal, I. (2013). El norte santafesino, una frontera de colonización entre la barbarie y la civilización, 1860-1880. Cuadernos de Antropología, 9, 227-250.

Dosztal, I. (2015). "Estamos invitados a tomar el té" en la Casa de la Administración de la Alexandra Colony. Alejandra, Santa Fe (1870-1885). Revista de Arqueología Histórica Argentina y Latinoamericana, 9(2), 27-56.

Ensinck, O. L. (1978). Historia de la inmigración y la colonización en la Provincia de Santa Fe. Buenos Aires, Argentina: Fundación para la Educación y la Cultura.

Fernández, S. R. (2007). Los estudios de historia regional y local de la base territorial a la perspectiva teórico-metodológica. En S. R. Fernández (Comp.), Más allá del territorio. La historia regional y local como problema. Discusiones, balances y proyecciones. Rosario: Argentina: Prohistoria Ediciones.

Gallo, E. (2004). La pampa gringa. La colonización agrícola en Santa Fe (1870-1895). Buenos Aires, Argentina: Edhasa.

Grobet, M. (1875). Expedición contra los indios montaraces (Tomo 42, apéndice 25). Santa Fe, Argentina: Archivo General de la Provincia de Santa Fe, Archivo de Gobierno.

Hough, R. (1992). Edward and Alexandra: Their private and public lives. Londres: Hodder \& Stoughton Ltd.

Hudson, E. A. (1870). Memoria de mensura campo Thompson, Bonner y Compañía. Argentina: Servicios de Catastro e Información Territorial. Dirección de Obras Públicas de la Provincia de Santa Fe.

Iñigo, N. (1984). Campañas militares y clase obrera. Chaco 1870-1930. Buenos Aires, Argentina: Centro Editor de América Latina. 
Iñigo, N. (1989). La violencia como potencia económica: Chaco 1870-1940. El papel del Estado en un proceso de creación de condiciones para la constitución de un sistema productivo rural. Buenos Aires, Argentina: CEAL.

Iriondo, M. (2007). El Chaco Santafesino-Neógeno y Geomorfología. Comunicaciones del Museo Provincial de Ciencias Naturales "Florentino Ameghino", 13, 1-23.

Iriondo, U. de (1876). Apuntes para una historia de la provincia de Santa Fe. Santa Fe, Argentina: Junta Provincial de Estudios Históricos.

Larguía, J. (1876). Informe relativo a las colonias de la provincia de Santa Fe. Buenos Aires, Argentina: Imprenta y Litográfica El Courrier del Plata.

Madol, H. R. (1940). The private life of queen Alexandra: As viewed. Londres: Hutchinson \& Co.

Maffucci, J. L. (2007). Indios, inmigrantes y criollos en el nordeste santafesino (18601890): Un caso de violencia en una sociedad de frontera. Andes, (18), 275-302.

Mateo, J. (1997). Población, parentesco y red social en la frontera. Lobos (provincia de Buenos Aires) en el siglo XIX (Tesis de maestría). Universidad Internacional de Andalucía, Sede Iberoamericana Santa María de la Rábida, España.

Perkins, W. (1867). Relación de la expedición a El Rey en el Chaco. Rosario, Argentina: Imprenta del Ferrocarril.

Quijada, M. (2000). Indígenas: Violencia, tierras y ciudadanía. En M. Quijada, C. Bernand, y A. Schneider (Comps.), Homogeneidad y nación con un estudio de caso: Argentina, siglos XIX y XX (pp. 57-92). Madrid, España: Consejo Superior de Investigaciones Científicas, Centro de Humanidades, Instituto de Historia, Departamento de Historia de América.

Ratto, S. (1996). Conflictos y armonías en la frontera bonaerense (1832-1840). Entrepasados, 6(11), 21-34.

Ratto, S. (2003). El debate de la frontera a partir de Turner. La new western history, los borderlands y el estudio de las fronteras latinoamericanas. Boletín del Instituto de Historia Argentina y Americana Dr. Emilio Ravignani, (24), 105-126.

Rocchietti, A. M. (2008). Bajo fuego. Sociedad y cultura en la frontera del sur. Córdoba, Argentina: Universidad Nacional de Río Cuarto.

Schiera, A. (2005). Uso y abuso del concepto de resiliencia. Revista de Investigaciones en Psicología, 8(2), 129-135.

Spota, J. C. (2009). Los fortines en la frontera chaqueña (1862-1884). Un enfoque desde la antropología histórica en relación con la teoría de las organizaciones. Memoria Americana, 17(1), 85-117.

The Chaco Indians and colonization in Santa Fe. (11 de noviembre de 1871). The Standard. Colecciones Especiales, Archivo de la Universidad de San Andrés, Victoria, Buenos Aires, Argentina.

Tourn, G. A. (1999). Cartas desde el Pájaro Blanco (boletín Ixıv [traducciones del archivo epistolar]). Santa Fe, Argentina: Museo Regional, Casa de la Cultura.

Tourn, G. A. (2001). Colonia Alexandra. Un lugar del pájaro blanco. Santa Fe, Argentina: Imprenta SERV-GRAF.

Trinchero, H. (2000). Los dominios del demonio. Civilización y barbarie en las fronteras de la nación. Buenos Aires, Argentina: Eudeba.

Trinchero, H. (2007). Aromas de lo exótico. Retornos del objeto para una crítica del objeto antropológico y sus modos de reproducción. Buenos Aires, Argentina: Ediciones Sb. 
Turner, F. J. (1921). The frontier in american history. Nueva York, Estados Unidos de América: Dover Publications.

Vogel, F. (1946). The life of William T. Moore. Texas, Estados Unidos de América.

Weber, D. J. (1986). Turner, the Boltonians, and the borderlands. The American History Review, 91(1), 66-81.

Wilcken, G. (1873). Las Colonias. Informe sobre el estado actual de las colonias agrícolas de la República Argentina, presentado a la Comisión Central de Inmigración. Buenos Aires, Argentina: La Sociedad Anónima.

Weguelin, A. (29 de enero de 1871). [Carta para Percy Heurtley]. Archivo personal de Guido A. Tourn Pavillon.

Zeballos, E. (1984). La rejión del trigo. Madrid, España: Hyspamérica Ediciones.

Irene Dosztal

Argentina. Doctora en Humanidades y Artes Mención: Antropología, por la Universidad Nacional de Rosario. Investigadora del Centro de Investigaciones Socio-históricas Regionales (Ishir-Conicet), Nodo Centro de Estudios Sociales Regionales (Cesor). Autora de: "Estamos invitados a tomar el té" en la casa de la administración de la Alexandra Colony. Alejandra, santa fe (1870-1885). Revista de Arqueología Histórica Argentina y Latinoamericana, 9(2), 27-56, 2015. Sus más recientes artículos se enfocan en análisis holísticos arqueohistóricos asociados a la colonización de la Provincia de Santa Fe durante la segunda mitad del siglo XIX. 